\title{
Decay of sperm obtained from epididymes of wild ruminants depending on postmortem time
}

\author{
F. Martinez-Pastor ${ }^{\mathrm{a}}$, C. Guerra ${ }^{\mathrm{b}}$, M. Kaabi ${ }^{\mathrm{b}}$, A.R. Diaz ${ }^{\mathrm{a}}$,

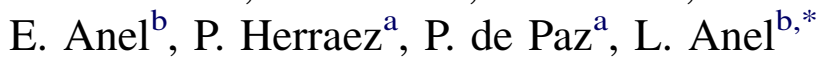 \\ ${ }^{a}$ Department of Cell Biology and Anatomy, Faculty of Biology, Spain \\ ${ }^{\mathrm{b}}$ Reproduction and Obstetrics, Veterinary Clinic Hospital, University of León, León 24071, Spain \\ Received 1 February 2004; received in revised form 18 March 2004; accepted 18 March 2004
}

\begin{abstract}
We have carried out a study on the effect of postmortem time (PT) in some characteristics of epididymal sperm salvaged from hunted Iberian red deer and roe deer. Testis were collected, identified, refrigerated down to $5{ }^{\circ} \mathrm{C}$, and sent to our laboratory by the wardens of the hunting reserves. This way, samples were delivered at different times postmortem. Sperm were extracted from the cauda epididymis by means of cuts. Analyzed parameters were: osmolality, $\mathrm{pH}$, motility—both subjectively and with CASA, HOS test reactivity, acrosomal status and viability (assessed with propidium iodide). Osmolality and $\mathrm{pH}$ rose with prolonged postmortem time, possibly due to tissue decomposition. Most sperm quality parameters negatively correlated with PT. Besides, when comparing PT classes (groups of $24 \mathrm{~h}$ for red deer and $30 \mathrm{~h}$ for roe deer), we could appreciate that motility was more affected by PT than other quality variables. Progressive motility was especially impaired. We also classified the samples in high, medium and low quality for each PT group (considering progressive motility, intact acrosomes and reactivity to the HOS test), and it was clear that after 2 days the number of high quality samples was testimonial, and after several days, we almost found only low quality samples. In conclusion, epididymal sperm from Iberian red deer and roe deer undergo a decrease of quality with PT, but it could stay acceptable within many hours postmortem. There are implications for wildlife conservation programs, as epididymal sperm is a good source of germplasm. If valuable animals die and it is not possible to process their sperm immediately, it may still be possible to obtain viable spermatozoa many hours later.
\end{abstract}

(C) 2004 Published by Elsevier Inc.

Keywords: Red deer; Roe deer; Postmortem recovery; Epididymal sperm; Refrigeration; Epididymal storage

* Corresponding author. Tel.: +34-987-2913-20; fax: +34-987-2013-22.

E-mail address: dsalar@unileon.es (L. Anel). 


\section{Introduction}

The cervid species Iberian red deer (Cervus elaphus hispanicus) and roe deer (Capreolus capreolus) are appreciated trophies in Spain and are subjected to controlled hunting, both in state hunting reserves and in private properties. Populations are frequently constricted to small areas and separated by fences and other barriers, thus inbreeding and loss of genetic variability are a recurrent hazard [1]. There is also a great interest in keeping good trophies and autochthonous subspecies. Consequently, the interest in developing artificial reproduction techniques and genetic resource banks for these species has been increasing, considering the possibilities that this kind of approach offers [2-4]. Since males are hunted in numbers around the rut season, there is an available source of epididymal sperm.

Postmortem sperm recovery is an useful strategy for germplasm banking [5]. This technique allows to use the epididymal sperm reserves of deceased or hunted males, especially when semen collection by other ways would be difficult or impossible. Sperm stored in the cauda epididymis have usually good quality and a high level of maturation, being able to fertilize oocytes. To date, many studies have demonstrated that it is possible to obtain viable gametes postmortem. Furthermore, successful pregnancies have been achieved in many species using epididymal sperm for artificial insemination [6-10].

However, in order to get good quality samples, sperm collection and processing should be carried out immediately after the death of the animal. This is not always possible, especially regarding wild species. In these circumstances, animal death is generally unpredictable or it happens far away from laboratories and technicians. In the case of Iberian red deer and roe deer in Spain, samples sometimes cannot be delivered immediately to the laboratory, since hunting often takes place in the wild. Even though sperm cells can survive for some time in the epididymes of dead animals, their quality deteriorates with time, because of the changes related to body death and decomposition $[8,11]$.

Therefore, to determine the quality and decay of sperm stored in epididymes postmortem, some studies have been carried out in a few species, such as mice [8,12-15], boar [16], dog [17], some African wild species [18-20], mouflon [6] and Iberian red deer [2123]. In general, these works agree that there is a general deterioration in sperm quality depending on time postmortem, specially marked in the first hours, and that refrigeration of the epididymes down to around $5{ }^{\circ} \mathrm{C}$ is the best strategy to lower this damage. However, there are many dissimilarities between species, possibly due to differences on cold shock endurance of epididymal sperm.

In this work we have evaluated the quality of sperm samples obtained from Iberian red deer and roe deer epididymes, which were delivered to our laboratory at different times postmortem. Since refrigeration devices are widely available, testicles of hunted animals could be kept at $5{ }^{\circ} \mathrm{C}$ during its storage. Our objective was to determine the effect of postmortem time on sperm quality and the characteristics of its decline, in the same conditions that often occur when samples are collected in the wild and immediate transport to the laboratory is not always possible. This work is included in a long-term plan dedicated to setting up a germplasm bank for wild ruminant species in the North of Spain, obtaining sperm samples from hunted animals. 


\section{Material and methods}

\subsection{Sample collection}

Samples were collected from recently shot Iberian red deer (C. elaphus hispanicus) and roe deer (C. capreolus) in the hunting reserves of Ancares, Mampodre and Picos de Europa (León, North of Spain). Collection was carried out during the breeding season (rut) of this species (autumn for Iberian red deer and beginning of summer for roe deer), by the official gamekeepers of the hunting reserves. These hunting reserves are directed by the regional government (Junta de Castilla y León), and hunting is very selective and regulated following population control criteria. Harvest plans followed Spanish Harvest Regulation, Law 4/96 of Castilla y León, which conforms of European Union Regulation, and the Annual Hunting Regulation, which establish species and number of individuals that can be hunted. Furthermore, species and number of individuals that can be hunted, and the exact periods of the year in which hunting can take place, are reviewed each year by the Annual Hunting Regulation. Animal manipulations were performed in accordance with the Spanish Animal Protection Regulation, RD223/1998, which conforms to European Union Regulation 86/609 and adheres to guidelines established in the Guide for Care and Use of Laboratory Animals as adopted and promulgated by the American Society of Andrology.

Scrotum, including testicles and epididymes, was removed from the carcass and refrigerated down to $5{ }^{\circ} \mathrm{C}$ as soon as possible. Date and time of death, genitalia collection and refrigeration were noted and attached to the corresponding sample. Refrigerated samples were sent to our laboratory in the Veterinary Clinic Hospital of the University of León (Spain). Postmortem time (PT) was defined as the interval between the death of the animal and the arrival of the sample to our laboratory. A total of 199 Iberian red deer samples and 72 roe deer samples were delivered.

\subsection{Sample processing}

Sample processing was performed in a walk-in fridge $\left(5^{\circ} \mathrm{C}\right)$ immediately after its arrival. Epididymes were dissected and cleaned from connective tissue. Sperm were collected performing several incisions in the cauda epididymis with a surgical blade, and taking the white fluid emerging from the cut tubules. To diminish blood contamination, superficial blood vessels were cut previously, wiping its content and drying cauda surface thoroughly. Sperm from both epididymes of the same animal were put together in a plastic cone, conveniently labeled, and used in the subsequent analysis.

\subsection{Sperm assessment}

All chemicals were acquired from Sigma (The Netherlands). Media were not bought as such, but prepared in our laboratory as described.

Osmolality and $\mathrm{pH}$ of each sample were measured using a cryoscopic osmometer (Osmomat-030, Gonotec ${ }^{\mathrm{TM}}$; Berlin) and an electronic pH-meter (CG 837, Schott $^{\mathrm{TM}}$; Mainz), respectively. 
For motility assessment, $5 \mu \mathrm{L}$ of sample were diluted in $500 \mu \mathrm{L}$ of Hepes medium (20 mmol/L Hepes, $197 \mathrm{mmol} / \mathrm{L} \mathrm{NaCl}, 2.5 \mathrm{mmol} / \mathrm{L} \mathrm{KOH}, 10 \mathrm{mmol} / \mathrm{L}$ glucose; $\mathrm{pH}$ 7, $400 \mathrm{mOsm} / \mathrm{kg}$ ). Diluted samples were put on a warming plate at $37^{\circ} \mathrm{C}$ during a minimum of $20 \mathrm{~min}$, and read within $20 \mathrm{~min}$. We checked that there were not motility variations within this time period. A Makler counting chamber $(10 \mu \mathrm{m}$ depth; Haifa Instruments, Israel), warmed up to $37^{\circ} \mathrm{C}$, was filled with $5 \mu \mathrm{L}$ of sample and examined with a phase contrast microscope (Nikon Labophot-2; negative contrast optics), on a warming stage at the same temperature. At least five fields were observed at $200 \times$. Total motility (percentage of cells exhibiting any kind of movement) and progressive motility (percentage of cells with straight movement) were subjectively estimated. Besides, a CASA system coupled to the same microscope was used to objectively assess motility (Motility Analyzer v. 7.4G, Hamilton-Thorne Research ${ }^{\mathrm{TM}}$ ), collecting the following parameters: total motility (\%), progressive motility $(\%)$, average path velocity $(\mu \mathrm{m} / \mathrm{s}$; VAP), straightness (\%; STR), and amplitude of the lateral movement of the head ( $\mu \mathrm{m} ; \mathrm{ALH})$. At least five fields and 200 cells were recorded at $200 \times$, using an image acquisition rate of 25 frames/s and an acquisition time of $0.8 \mathrm{~s}$.

Aliquots of the samples were fixated in a glutaraldehyde solution $(5 \mu \mathrm{L}$ in $500 \mu \mathrm{L} ; 2 \%$ glutaraldehyde in an aqueous solution of $146 \mathrm{mmol} / \mathrm{L}$ glucose, $34 \mathrm{mmol} / \mathrm{L}$ sodium citrate tribasic dihydrate and $24 \mathrm{mmol} / \mathrm{L}$ sodium bicarbonate). Five microliters were put on a microscope slide, covered with a coverslip and observed with a phase contrast microscope $(400 \times)$ [24]. Acrosomal status (percentage of cells with an intact acrosome) was evaluated counting at least 100 cells.

The functional integrity of the sperm plasma membrane was evaluated using the hypoosmotic swelling test (HOS test). Five microliters of sample were diluted in $500 \mu \mathrm{L}$ of a hypoosmotic sodium citrate solution $(100 \mathrm{mOsm} / \mathrm{kg})$. After $18 \mathrm{~min}$ at room temperature, samples were fixed with a drop of glutaraldehyde solution. Responsiveness to the test was determined counting a minimum of 100 cells with a phase-contrast microscope $(400 \times)$. HOS test reactivity was defined as percentage of positive cells (those with a swollen tail) [25].

Sperm viability was assessed using the fluorescent dye propidium iodide (PI). Five microliters of sample were diluted in $500 \mu \mathrm{L}$ of PI solution $(5 \mu \mathrm{g} / \mathrm{mL}$ PI in the same Hepes solution described in motility assessment). Samples were kept $10 \mathrm{~min}$ in the dark before being analyzed with a epifluorescence microscope (Nikon Optiphot; 400×, 450-490 nm excitation filter, $510 \mathrm{~nm}$ dichroic beam splitter, $520 \mathrm{~nm}$ barrier filter). At least 100 cells were counted, and the percentage of non-stained cells (viable spermatozoa) was noted [26].

\subsection{Data processing and statistical analysis}

Statistical analysis were carried out using the SAS ${ }^{\mathrm{TM}}$ package (SAS Institute, Cary, NC). Since collected data was not normally distributed and heavily tailed, non-parametric test were preferred. First, we obtained the Spearman correlation coefficients between PT and sperm parameters, in order to detect possible relationships between them. To study the variation of sperm parameters along PT, we divided it in many intervals, and carried out a comparison. We used 24-h intervals for Iberian red deer (from 0 to $168 \mathrm{~h}$, plus an extra class for PT $>168 \mathrm{~h}$ ). For roe deer, due to lower number of samples and their unbalanced 
distribution among 24-h groups, we used 30-h intervals instead (from 0 to 150, plus and extra class for PT $>150 \mathrm{~h}$ ). A multiple group comparison was carried out using the Kruskal-Wallis test, followed by a group pairwise comparison (Wilcoxon rank-sum test) when differences were significant $(P<0.05)$. The mean and standard deviation of the PT $>168$ and $>150 \mathrm{~h}$ classes were, respectively, $208 \pm 57 \mathrm{~h}$ and $226 \pm 74 \mathrm{~h}$.

Besides, in order to describe the evolution of the general quality of the samples and compare both species, the samples were classified accordingly to their quality in $24 \mathrm{~h}$ PT groups. Quality was defined by the progressive motility, HOS test reactivity, and acrosomal status of each sample. A sample was included in the high quality group if all the three parameters were equal or higher than $60 \%$. If any of them was lower than $60 \%$, but all of them were at least $30 \%$, the sample was included in the medium quality group. Whenever any parameter was below $30 \%$, the sample was included in the low quality group. The distribution of quality groups between PT classes was compared using the $\chi^{2}$ test. When the conditions made unsuitable the application of this test, the Fisher's exact test was used instead. $P<0.05$ was used for statistical significance.

\section{Results}

\subsection{Data collected}

Almost all the samples could be analyzed for $\mathrm{pH}$, osmolality, subjective motility assessment, HOS test, acrosome integrity, and viability; however, some samples were rejected because of bad aspect or improper refrigeration (Table 1). CASA was available only for 55\% (92) and 39\% (26) of red deer and roe deer analyzed samples, respectively, thus there was a lower sample number available in these cases. We have observed a high variation within PT groups, which is evident considering the wide interquartil ranges (Figs. 1-4). It was not clear if this variation corresponded to individual differences between males, to collection and refrigeration conditions, or to other factors.

\subsection{Correlation analysis}

Analysis of the correlations between PT and the studied parameters (Table 2) rendered similar results for both species. Motility (except for STR in roe deer), HOS test reactivity, intact acrosomes and viability presented negative correlations with PT. On the other hand, osmolality and $\mathrm{pH}$ showed positive correlations. In general, correlations were highly or

Table 1

Number of samples for each species and PT classes

\begin{tabular}{|c|c|c|c|c|c|c|c|c|c|}
\hline Red deer & [0-24] & ]24-48] & ]48-72] & ]72-96] & ]96-120] & ]120-144] & ]144-168] & $>168$ & Total \\
\hline$n$ & 16 & 28 & 39 & 20 & 21 & 12 & 17 & 15 & 168 \\
\hline Roe deer & [0-30] & ]30-60] & ]60-90] & ]90-120] & ]120-150] & $>150$ & Total & & \\
\hline$n$ & 6 & 23 & 8 & 6 & 6 & 18 & 67 & & \\
\hline
\end{tabular}

Note that not all the samples delivered (199 for red deer and 72 for roe deer) were analyzed. 


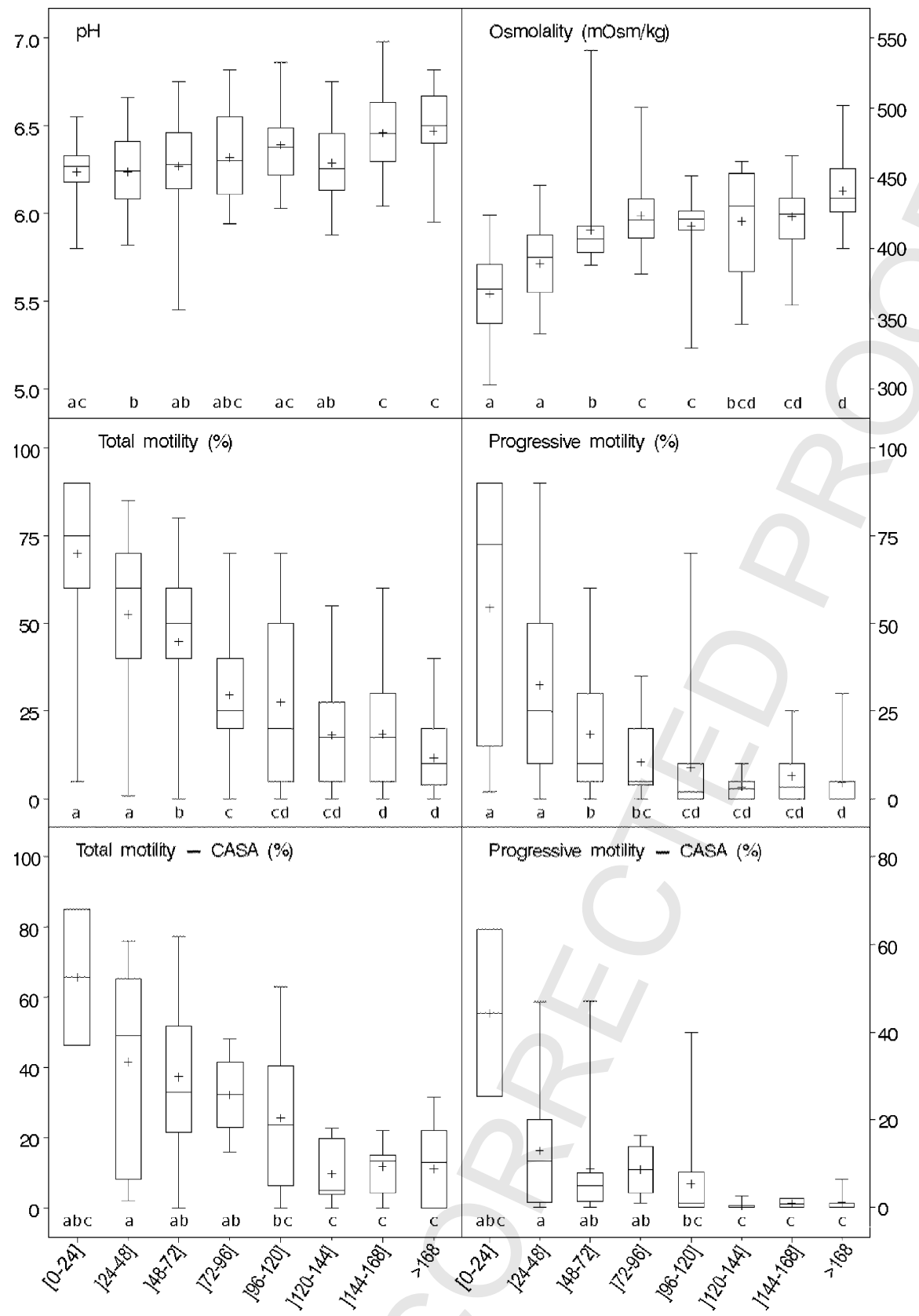

Fig. 1. Red deer: evolution of sperm $\mathrm{pH}$, osmolality, total motility and progressive motility (subjective and CASA) depending on postmortem time (time intervals in hours). Lower and upper limits of the boxes indicate the first and third quartiles, respectively, and the horizontal line inside the boxes indicates the median score. The whiskers reach the maximum and minimum values of the range. The mean is shown with a cross. Different letters on the bottom of a plot indicate significant differences between PT classes $(P<0.05)$. 


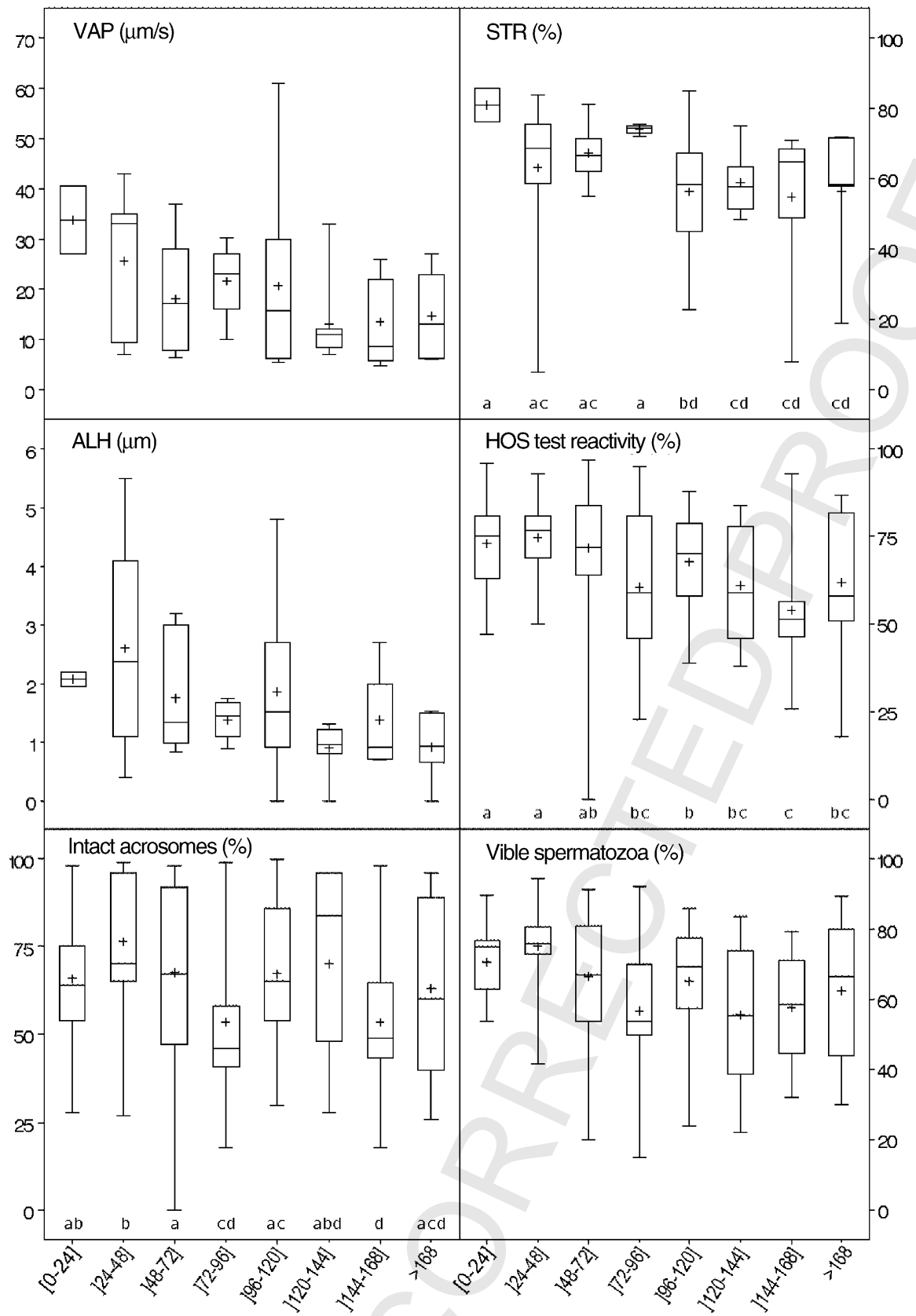

Fig. 2. Red deer: evolution of sperm VAP, STR, ALH, HOS test reactivity, acrosomal integrity and viability depending on postmortem time (time intervals in hours). Lower and upper limits of the boxes indicate the first and third quartiles, respectively, and the horizontal line inside the boxes indicates the median score. The whiskers reach the maximum and minimum values of the range. The mean is shown with a cross. Different letters on the bottom of a plot indicate significant differences between PT classes $(P<0.05)$. 


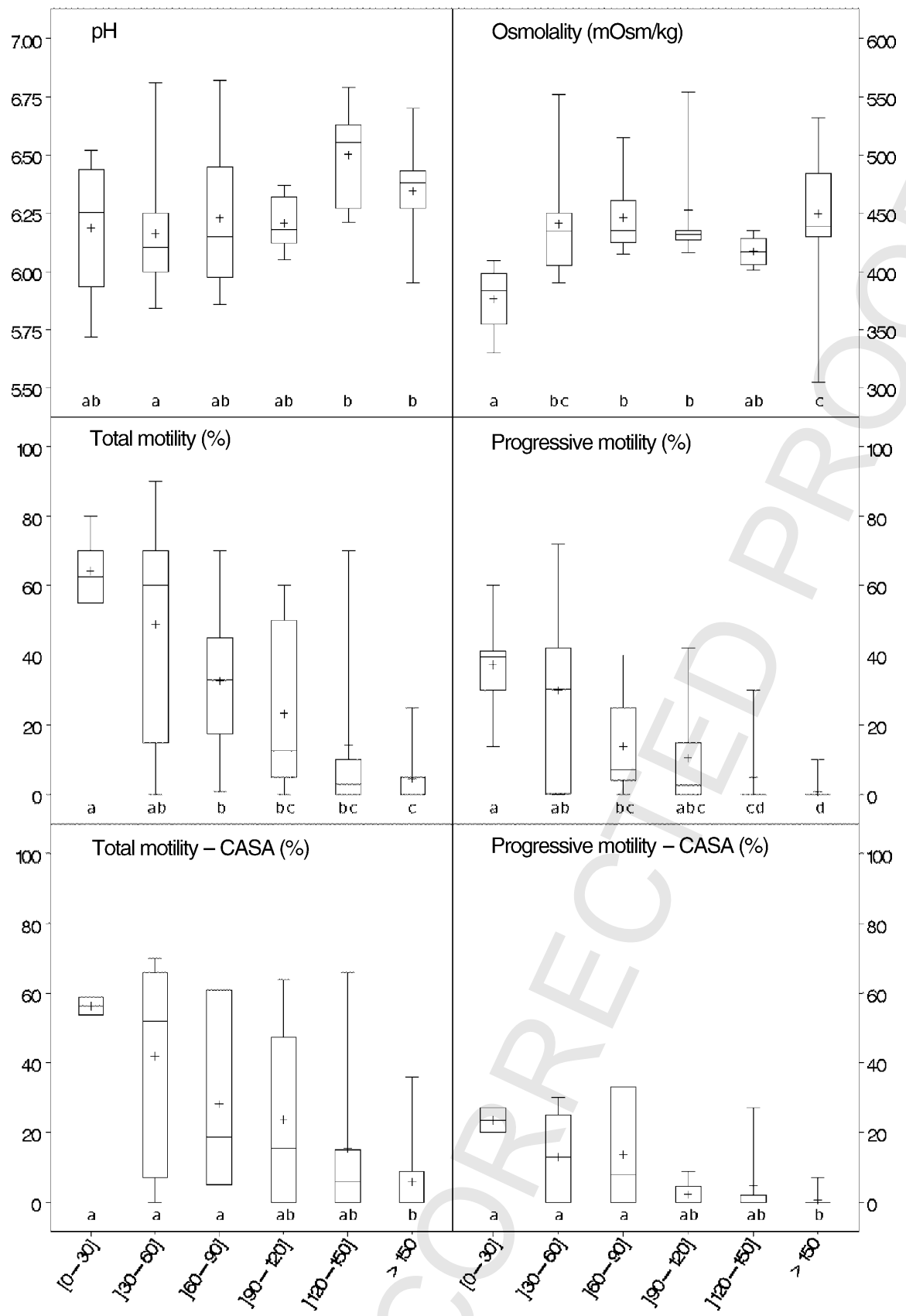

Fig. 3. Roe deer: evolution of sperm $\mathrm{pH}$, osmolality, total motility and progressive motility (subjective and CASA) depending on postmortem time (time intervals in hours). Lower and upper limits of the boxes indicate the first and third quartiles, respectively, and the horizontal line inside the boxes indicates the median score. The whiskers reach the maximum and minimum values of the range. The mean is shown with a cross. Different letters on the bottom of a plot indicate significant differences between PT classes $(P<0.05)$. 


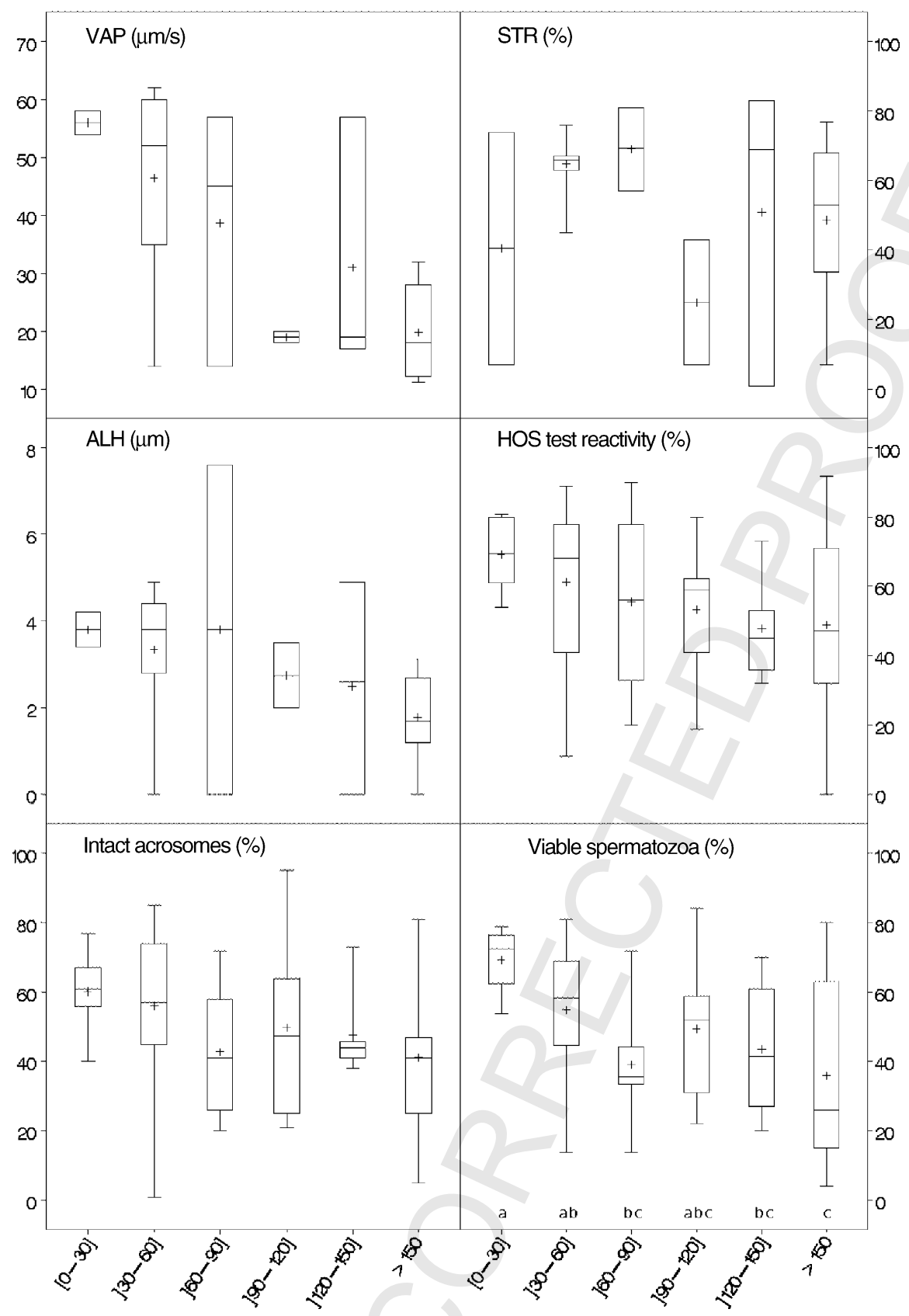

Fig. 4. Roe deer: evolution of sperm VAP, STR, ALH, HOS test reactivity, acrosomal integrity and viability depending on postmortem time (time intervals in hours). Lower and upper limits of the boxes indicate the first and third quartiles, respectively, and the horizontal line inside the boxes indicates the median score. The whiskers reach the maximum and minimum values of the range. The mean is shown with a cross. Different letters on the bottom of a plot indicate significant differences between PT classes $(P<0.05)$. 
Table 2

Correlations between PT and sperm parameters (Spearman coefficients and significance)

\begin{tabular}{lllllll}
\hline & $\mathrm{pH}$ & Osmolality & $\mathrm{TM}^{\mathrm{a}}$ & $\mathrm{PM}^{\mathrm{b}}$ & $\mathrm{TM}^{\mathrm{a}}(\mathrm{CASA})$ & $\mathrm{PM}^{\mathrm{b}}(\mathrm{CASA})$ \\
\hline Red deer & $0.30^{* * *}$ & $0.57^{* * *}$ & $-0.62^{* * *}$ & $-0.56^{* * *}$ & $-0.54^{* * *}$ & $-0.52^{* * *}$ \\
Roe deer & $0.39^{* *}$ & $0.35^{* *}$ & $-0.64^{* * *}$ & $-0.68^{* * *}$ & $-0.51^{* * *}$ & $-0.55^{* * *}$ \\
& VAP & STR & ALH & $\begin{array}{l}\text { HOS test } \\
\text { reactivity }\end{array}$ & $\begin{array}{l}\text { Intact } \\
\text { acrosomes }\end{array}$ & Viability \\
Red deer & $-0.36^{* *}$ & $-0.35^{* * *}$ & $-0.41^{* *}$ & $-0.32^{* * *}$ & $-0.21^{* * *}$ & $-0.26^{* * *}$ \\
Roe deer & $-0.54^{* *}$ & -0.12 & $-0.40^{* *}$ & $-0.37^{* *}$ & $-0.36^{* *}$ & $-0.49^{* * * *}$ \\
\hline
\end{tabular}

\footnotetext{
a Total motility.

${ }^{\mathrm{b}}$ Progressive motility.

${ }^{*} P<0.05$.

** $P<0.01$.

${ }^{* * *} P<0.001$.
}

very highly significant. Correlation coefficients were low in most cases, though. Remarkably, PT and total and progressive motility, both by subjective and CASA assessments, rendered correlation coefficients above 0.5 .

\subsection{Comparison between PT classes}

A summary of the data grouped by PT classes is shown in Figs. 1-4. In general, data followed the corresponding trend indicated by the correlation coefficients. However, we did not find significant variations in many cases, especially for roe deer, possibly due to the high variability of the samples. In fact, for roe deer, only the classes ]30-60] h and $>150 \mathrm{~h}$ included more than 10 cases (Table 1), and, as said before, only a fraction of these samples was analyzed by CASA, therefore this could be another reason for the lack of significance.

In both species, $\mathrm{pH}$ and osmolality varied differently. Whereas $\mathrm{pH}$ seemed to rise only slightly, and this rising was only evident in the last PT classes, osmolality increased early (after $48 \mathrm{~h}$ for red deer and $30 \mathrm{~h}$ for roe deer). Beyond this point, osmolality continued rising clearly in the case of Iberian red deer. However, for roe deer, it stalled and no further increase was noted.

Total motility decreased steadily along the studied time periods, but progressive motility dropped around the third day. By the fourth day, progressive motility was practically 0 . This was observed both in subjective and CASA parameters. Other motility parameters, yielded by the CASA system, showed a steady decrease, only significant for STR in red deer, though. For roe deer, STR was still high in the last classes.

HOS test reactivity and acrosomal status showed significant differences between groups only for Iberian red deer. In this species, it could be appreciated that the proportion of spermatozoa positive to the HOS test decreased with PT (but only in a low percentage). However, in the case of acrosomal status, the results were less evident, since there were many samples with high values in the last PT classes.

The case of the viability was completely opposite, because, although both species showed a diminution of viability values through PT, only roe deer data rendered 
statistical differences between PT groups. In this case, we found one important difference between the two species, since both of them had similar viability values in the early PT groups (median value above $70 \%$ ), but it diminished to $66.5 \%$ in the $>168 \mathrm{~h}$ group for red deer, whereas it dropped to only $26 \%$ in the $>150 \mathrm{~h}$ group for roe deer.

\subsection{Distribution of quality groups within PT classes}

Distribution of the samples in high, medium, and low quality for each PT class, and results of $\chi^{2}$ test are shown in Fig. 5. For Iberian red deer, nearly $40 \%$ of the samples belonged to the high quality group when processed before the first $24 \mathrm{~h}$ postmortem, summing more than $60 \%$ together with medium quality samples, although differences in the distributions were not still significant. However, in the next $24 \mathrm{~h}$, the proportion of high quality samples was halved, and low quality samples rose up to $50 \%$. After $120 \mathrm{~h}$ postmortem, none of the samples could be considered even as of medium quality.

Roe deer samples had a similar distribution than those of red deer. However, the distribution is less clear due to the lower $n$ in each PT class (only the ]24-48], ]48-72], and $>168 \mathrm{~h}$ classes had more than 10 samples each). Apparently, the increase of the proportion of bad quality samples was slower than in the case of red deer (comparing 148-72] h classes), but from this point forward the trend was almost identical. Before using $\chi^{2}$ test, those groups that seemed to be homogeneous were joined in order to increase the number of samples in each one and get reliable results. Thus, data from ]24-48] and 148-72] h, and ]72-96], ]96-120], ]120-144] and ]144-168] h were put together. Lack of significance between [0-24] and ]24- 72] h groups is logical, as [0-24] h group included only four samples.
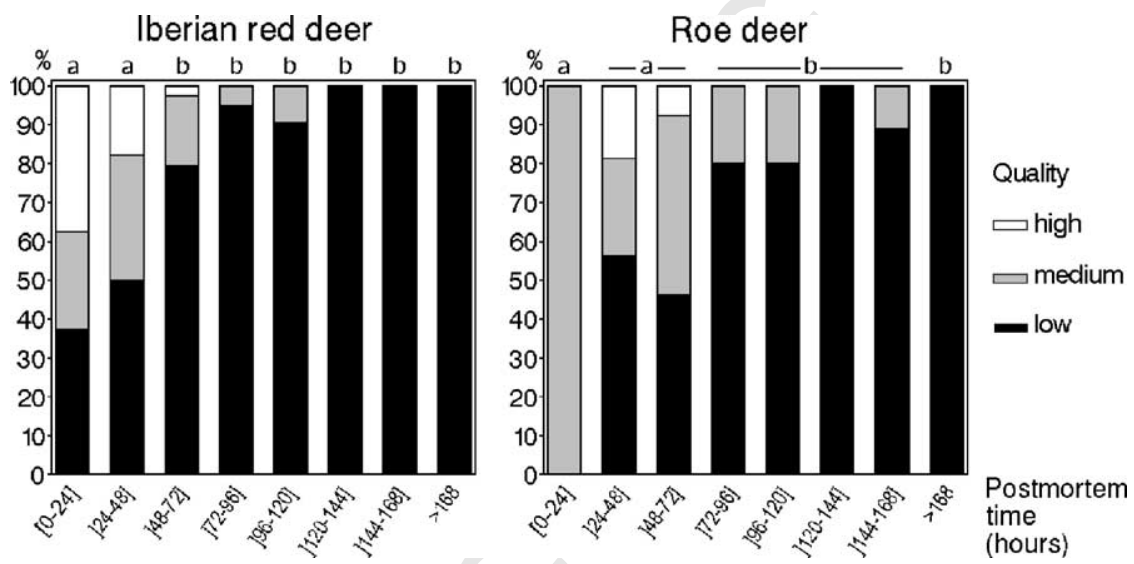

Fig. 5. Distribution of samples in high, medium, and low quality groups for each species and PT classes. High quality: progressive motility, HOS test reactivity and acrosomal status $>60 \%$; medium quality: any of these parameters $=60 \%$ but $>30 \%$; low quality: any of these parameters $<30 \%$. Different letters indicate statistical differences $\left(\chi^{2} ; P<0.05\right)$. In the case of roe deer, ]24-48] and ]48-72], and ]72-96], ]96-120], ]120-144] and ]144-168] were considered as single classes for the $\chi^{2}$ test. 


\section{Discussion}

In this study we have shown that the quality of the sperm stored in the cauda epididymis of Iberian red deer and roe deer decays with PT. However, for some time, the quality could be high enough to consider the salvage of samples. We have to consider that this work is a preliminary step to establish a germplasm bank for wild ruminants in the North of Spain, and that most of the samples would be obtained from hunted animals. Hunting in that area is very selective, and there is a tendency to collect animals of good aspect, considering trophy and body shape, which are highly heritable traits. Thus, the interest of studying the characteristics of these samples and the impact of postmortem time on their quality.

There are many studies on the deleterious effect of PT in epididymal sperm. Nevertheless, these works also show that it is possible to obtain good quality and even fertile sperm from refrigerated epididymes many hours or days postmortem Garde et al. [21], Sankai et al. [15], Yu and Leibo [17]. Furthermore, some works describe that viable spermatozoa could be retrieved even if the epididymes were stored at ambient temperature for some hours. Christian et al. [27] reported motile spermatozoa in mice $24 \mathrm{~h}$ postmortem at room temperature. Other authors confirmed that sperm in these conditions were able to penetrate mice or ewe oocytes [14,28], or produce live mice offspring [8].

Several works on this subject have been carried out in cervids [11,21,23,29], but there are important methodological differences between these other studies and ours. The usual protocol consists in the transport of the genitalia to the laboratory just after the death of the animal, where they are refrigerated in controlled conditions. On the other hand, we planned to carry out this study in the same conditions that usually occur when samples are collected in the wild, and there is no possibility to immediately transport them to the laboratory. Briefly, the testicles are removed from the animal, refrigerated, and delivered to our laboratory as soon as possible, in an insulated container. All this process is carried out by the gamekeepers of the hunting reserves, and the refrigeration and storage are performed in home refrigerators. In this manner, samples arrived to our laboratory one or two times per week during the hunting season, and we processed samples of a wide range of postmortem times, from few hours to a week or more. It was important for us to follow these same collecting and delivery protocol, since in the event of establishing a germplasm bank in this location, the most important source of samples would be this one. This methodology is currently difficult to standardize, thus the interest in knowing what the impact on the samples could be.

As a consequence, we had many sources of variation that could influence the quality of the samples. This can be appreciated in the high variability between different samples. Apart form the individual differences between males, the most important of these sources of variation was the temperature the samples were exposed to during the postmortem time interval. Since hunting takes place in mountainous spots, a wounded animal is often tough to track. Thus, some samples were exposed to ambient temperature for several hours before they could be refrigerated. This should not be worrying in the case of red deer, as it is hunted by autumn, when temperature is usually low in the mountains of the North of Spain, but roe deer is hunted in the summer, when temperatures generally vary from warm to hot. 
The refrigeration of the samples is another factor of variation, because we were unaware of the conditions of the gamekeepers' refrigerators and the possible incidents in their operation. Furthermore, there might be a interaction between individuals and the impact of temperature changes on the spermatozoa, so the sperm of one male could endure these temperature variations whereas the sperm of another one could not [30].

Nevertheless, we considered that these sources of variation were acceptable, since we wanted to study the quality of the samples that had actually endured the conditions described above. Nevertheless, we removed from our data those samples that were kept at ambient temperature more than $6 \mathrm{~h}$ after the death of the animal, or those we considered that had been kept in very bad conditions (frozen or rotten). Anyway, some authors have indicated that there is little decrease in the quality of the samples kept at room temperature for a few hours (6-15 h) [8,15,31]. Recently, Kaabi et al. [32] reported similar cleavage rates for oocytes inseminated with ram sperm from epididymes stored at room temperature or refrigerated, both at 24 and $48 \mathrm{~h}$ postmortem. All these studies indicated us that, although we could not control the time between the death of the animal and the refrigeration of the samples, this factor possibly did not affect seriously our samples.

As expected, we have detected a decrease of sperm quality along PT. The decrease of sperm quality with PT is due not only to sperm aging, but also to the processes inherent to tissue decomposition after death. Songsasen et al. [8], working with mice, described the degeneration of the epididymal tubules, showing that histological changes start as soon as $18 \mathrm{~h}$ postmortem. These changes were described as picnosis of the content of epithelial cells to the lumen of the tubules, followed apparently by the disruption of the epithelium some hours later. Hishinuma et al. [11] found similar changes in Sika deer epididymes several days postmortem. In our study, the increase of osmolality reflects the histological changes described by those authors. Concretely, Hishinuma et al. [11] indicated that degeneration at days 4 and 7 was more evident that at day 1 , which coincides with our findings regarding a significant increase of osmolality after several days postmortem. Moreover, the positive correlation between $\mathrm{pH}$ and PT indicates a loss of buffering capacity of the epididymal fluid. The rise of $\mathrm{pH}$ is less obvious than the increase of osmolality, as it was significant only after many days postmortem. This could indicate a good resilience of the buffering system inside the tubules. We have to consider that both osmolality and $\mathrm{pH}$ of the surrounding media have a great effect on sperm motility and metabolism [33]. Thus, the alterations of the physical environment of the epididymal sperm may have an important role in the loss of quality that we have observed, adding up to the intrinsic process of decay and aging of sperm due to PT.

In general, both Iberian red deer and roe deer epididymal sperm samples underwent a loss of quality when the epididymes were stored for more than $2-3$ days at $5{ }^{\circ} \mathrm{C}$. Progressive motility was the parameter that dropped more pronouncedly, followed by total motility, which coincides with results in other species [11,16,17,32]. For the other motility parameters, we think that more consistent results could have been achieved using a modern CASA system, which would have allowed to get sperm subpopulation parameters, instead of mean populational parameters, that can be deceiving [34]. We are preparing a complementary study in which sperm motility will be measured with a state-of-the-art CASA at different postmortem times, in order to perform a more complete study of motility. 
Considering recent studies in cervids, in a preliminary report on Iberian red deer [22], we obtained a similar trend on motility ( $24 \mathrm{~h}$ intervals over a 4-day period), with progressive motility dropping to almost nil at the end of the period. Hishinuma et al. [11], working with Sika deer, found that total motility significantly decreases as soon as the first day postmortem, and it continues falling when PT increases. Soler et al. [23] also detected a significant decrease of motility with PT in Iberian red deer, reporting that the sperm motility index (SMI) significantly reduces after 2 days, and it stabilized until the end of the experiment (4 days). Although we used different parameters considering motility (SMI combines total and progressive motility in the same parameter), the trend we reported in the case of Iberian red deer seems to be similar to those of these authors. However, mainly due to the abrupt decrease of progressive motility, our data show an early drop of quality, which marks a difference with the work of Soler et al. [23]. This discrepancy could be due to the differences in the experimental design (the epididymes were taken to the laboratory just after the death of the animals and kept in controlled refrigerated conditions), in the recollection time (November and December), and in the origin of the animals (South of Spain). Unfortunately, none of these studies reported $\mathrm{pH}$ or osmolality of the samples (sperm was immediately mixed with media after extraction). Considering our observations, it would be of great interest to extend this study, in order to clarify if the loss of quality of sperm motility is due not only to the normal process of aging, but also to the variations of the physical parameters of the epididymal fluid, and to what extent.

On the other hand, neither Hishinuma et al. [11] nor Soler et al. [23], found a reduction in sperm viability during the studied period ( 7 and 4 days, respectively). We have reported a highly significant negative correlation between viability and PT, but with low correlation coefficients. Comparing PT groups, we did not found significant differences for red deer, but for roe deer, which might indicate a difference between these species. Iberian red deer sperm possibly underwent a decrease in viability, as indicated by the correlation analysis, but it might be much more subtle. This can explain the lack of significant differences in the other studies, which also used a different method for viability assessment (eosin staining). Other quality parameters that endured well the postmortem conditions were the functionality of the plasma membrane (HOS test reactivity) and the acrosomal status. Both of them had highly significant negative correlations with PT for both species, but box plot distributions showed that differences between PT classes were small. In our previous study on red deer [22], we obtained similar results for HOS test reactivity, and, for acrosomal status and sperm viability, values were lower the fourth day postmortem. This would indicate that in fact these parameters are affected by postmortem time, but not as dramatically as motility.

Other authors have reported differences comparing related species. For instance, Sankai et al. [15], working with mouse, and Soler et al. [23], working with red deer, reported increasing numbers of sperm with abnormalities after 4 days postmortem. However, the former indicated a very high increase (more that $60 \%$ ) of bent tails, whereas the later found a much lower increase (around 20\%) of bent midpieces. Furthermore, Lubbe et al. [19], and Killian et al. [20] working with African wild Perissodactyls and African wild ruminants, respectively, reported some differences between similar species, regarding motility diminution along PT. In fact, cold-shock resistance varies pronouncedly between species, even between breeds or individuals [30]. Sankai et al. [15] interpreted the increasing 
proportion of sperm with bent tails as a consequence of the hardening of the plasma membrane due to low temperatures. This effect could contribute, at least in some extent, to the differences that we have find between red deer and roe deer, regarding plasma membrane integrity (sperm viability).

Finally, the classification of samples according to their quality showed that the proportion of samples classified as of low quality quickly grew with PT for the two species. Using a similar classification, Garde et al. [31], working with Iberian red deer, found that sperm quality seemed to reduce after $12 \mathrm{~h}$ postmortem, and the proportion of samples classified as excellent (progressive motility $>60 \%$, normal morphology $>40 \%$, intact acrosomes $>40 \%$, and HOS test reactivity $>40 \%$ ) dropped after that moment, reaching $0 \%$ in the $24-36 \mathrm{~h}$ period. In our work, our data followed a similar behavior, for both species. The chances of finding samples of acceptable quality before 2 days postmortem (under refrigeration) seemed to be good, but they quickly got much worse with increasing PT.

In conclusion, the quality of both Iberian red deer and roe deer epididymal sperm decreased with postmortem time, but this decrease was different for different parameters. Motility was the most affected one, and membrane and acrosomal integrity seemed to endure better the postmortem conditions. Besides, in both species we could still find acceptable samples after several days of refrigeration. Other authors $[14,17,23]$ recommended that if samples cannot be processed just after the death of the animal, they should be refrigerated, in order to process them when facilities were available. Considering our results, this advise seems reasonable, as the deleterious effect of storage at $5{ }^{\circ} \mathrm{C}$ seems to be acceptable, but only for few days (in our study this could be 2 days). Moreover, Sankai et al. [15] found similar results refrigerating mice epididymes protected either by mineral oil, body fat or inside the whole body. In our case, keeping testis and epididymes inside the scrotum should be enough to protect the cauda epididymis from desiccation, consequently avoiding complication in the collection of the sample in the field.

On the other hand, even if the samples have lost its motility because of a long storage, we have found that other characteristics might be still acceptable, so IVF or ICSI could be used to achieve fecundation and pregnancy in the case of valuable individuals or endangered species $[13,30]$. Nevertheless, further studies on the fertilizing capacity and the effect of frozen-thawing on Iberian red deer and roe deer epididymal spermatozoa, after being refrigerated for many days postmortem, must be carried out in order to confirm this possibility. In this sense, our group is carrying out further experiments in order to assess the suitability of these samples for cryopreservation.

\section{Acknowledgements}

This study has been supported by Junta de Castilla y León (AB29). The authors thank Juan José Martínez, César Gómez, Juan Carlos Peral, the Territorial Service of Environmental Affairs of León, and the gamekeepers of the hunting reserves of Picos de Europa, Mampodre and Ancares (León, Spain) for their collaboration in the collection of the samples used in this work; and Vanesa García, Mercedes Álvarez, Juan Daniel Muro, and Patri Martínez for their help in the processing of the samples. 


\section{References}

[1] Coulson T, Pemberton J, Albon S, Beaumont M, Marshall T, Slate J, et al. Microsatellites reveal heterosis in red deer. Proc R Soc Lond B 1998;265:489-95.

[2] Gilmore J, McGann L, Ashworth E, Acker J, Raath J, Bush M, et al. Fundamental cryobiology of selected African mammalian spermatozoa and its role in biodiversity preservation through the development of genome resource banking. Anim Reprod Sci 1998;53:277-97.

[3] Holt W, Pickard A. Role of reproductive technologies and genetic resource banks in animal conservation. Rev Reprod 1999;4:143-50.

[4] Leibo S, Songsasen N. Cryopreservation of gametes and embryos of non-domestic species. Theriogenology 2002;57:303-26.

[5] Foote R. Fertilizing ability of epididymal sperm from dead animals. J Androl 2000;21:355.

[6] Pérez S, Aguado M, Ayllon E, Garrido D, Montoro V, Garde J. Live birth of hybrid (O. musimon $\times O$. aries) lambs following intrauterine insemination in domestic sheep with mouflon semen obtained 40 hours postmortem. Theriogenology 1995;43:218 (abstract).

[7] Garde J, Ortiz N, García A, López A, Gallego L. Criopreservación post-mortem de material espermático e inseminación artificial en el ciervo ibérico. Arch Zootec 1998;47:351-6.

[8] Songsasen N, Tong J, Leibo S. Birth of live mice derived by in vitro fertilization with spermatozoa retrieved up to twenty-four hours after death. J Exp Zool 1998;280:189-96.

[9] Hewitt D, Leahy R, Sheldon I, England G. Cryopreservation of epididymal dog sperm. Anim Reprod Sci 2001;67:101-11.

[10] Ikeda H, Kikuchi K, Noguchi J, Takeda H, Shimada A, Mizokami T, et al. Effect of preincubation of cryopreserved porcine epididymal sperm. Theriogenology 2002;57:1309-18.

[11] Hishinuma M, Suzuki K, Sekine J. Recovery and cryopreservation of sika deer (Cervus nippon) spermatozoa from epididymides stored at 4 degrees C. Theriogenology 2003;59:813-20.

[12] Jishage K, Ueda O, Suzuki H. Fertility of mouse spermatozoa from cauda epididymis preserved in paraffin oil at $4{ }^{\circ}$ C. J Mamm Ova Res 1997; 14:45-8.

[13] An T, Wada S, Edashige K, Sakurai T, Kasai M. Viable spermatozoa can be recovered from refrigerated mice up to 7 days after death. Cryobiology 1999;38:27-34.

[14] Kishikawa H, Tateno H, Yanagimachi R. Fertility of mouse spermatozoa retrieved from cadavers and maintained at 4 degrees C. J Reprod Fertil 1999;116:217-22.

[15] Sankai T, Tsuchiya H, Ogonuki N. Short-term nonfrozen storage of mouse epididymal spermatozoa. Theriogenology 2001;55:1759-68.

[16] Kikuchi K, Nagai T, Kashiwazaki N, Ikeda H, Noguchi J, Shimada A, et al. Cryopreservation and ensuing in vitro fertilization ability of boar spermatozoa from epididymides stored at $4{ }^{\circ} \mathrm{C}$. Theriogenology 1998;50:615-23.

[17] Yu I, Leibo S. Recovery of motile, membrane-intact spermatozoa from canine epididymides stored for 8 days at 4 degrees C. Theriogenology 2002;57:1179-90.

[18] Friedmann Y, Lubbe K, Kilian I, Grobler D, Denniston R. Changes in motility and morphological characteristics of African buffalo (Syncerus caffer) sperm during storage of the epididymis. Theriogenology 2000;53:332 (abstract).

[19] Lubbe K, Bartels P, Kilian I, Friedmann Y, Godke RA. Comparing motility and morphology of horse, zebra and rhinoceros epididymal spermatozoa when cryopreserved with two different cryodiuents or stored at $4{ }^{\circ} \mathrm{C}$. Theriogenology 2000;53:338 (abstract).

[20] Killian I, Lubbe K, Bartels P, Friedmann Y, Denniston R. Evaluating epididymal sperm of African wild ruminants: longevity when stored at $4{ }^{\circ} \mathrm{C}$ and viability following cryopreservation. Theriogenology 2000;53:336 (abstract).

[21] Garde J, Ortiz N, García A, Gallego L, Landete CT, López A. Postmortem assessment of sperm characteristics of the red deer during the breeding season. Arch Androl 1998;41:195-202.

[22] Anel L, Guerra C, Alvarez M, Anel E, Martinez A, Boixo J, et al. Effect of post-mortem interval on quality of epididymal spermatozoa in Iberian red deer (Cervus elaphus hispanicus). Theriogenology 2002;57:577 (abstract).

[23] Soler A, Pérez-Guzmán M, Garde J. Storage of red deer epididymides for four days at $5{ }^{\circ} \mathrm{C}$ : effects on sperm motility, viability, and morphological integrity. J Exp Zool 2003;295A:188-99. 
[24] Saacke R, White J. Semen quality test and their relationship to fertility. In: 4th Technical Conference of Artificial Insemination Reproduction NAAB, 1972. p. 22.

[25] Jeyendran R, Van der Ven H, Perez-Pelaez M, Crabo B, Zaneveld L. Development of an assay to assess the functional integrity of the human sperm membrane and its relationship to other semen characteristics. $\mathrm{J}$ Reprod Fertil 1984;70:219-28.

[26] Brito LF, Barth AD, Bilodeau-Goeseels S, Panich PL, Kastelic JP. Comparison of methods to evaluate the plasmalemma of bovine sperm and their relationship with in vitro fertilization rate. Theriogenology 2003;60:1539-51.

[27] Christian C, Songsasen N, Leibo S. Presence of motile sperm in mice 24 hours postmortem. Theriogenology 1993;39:201.

[28] Garde J, Aguado M, Pérez S, Garrido D, Pérez-Guzmán M, Montoro V. Physiological characteristics of epididymal spermatozoa from postmortem rams. Theriogenology 1994;41:203 (abstract).

[29] Gizejewski Z, Soderquist L, Rodriguez-Martinez H. Post-mortem examination of genital organs and characteristics of epididymal spermatozoa from wild red deer stags Cervus elaphus carpaticus var. montanus. In: 2nd World Conf. Mt. Ungulates. Saint Vincent (Aosta), Italy; 1998. p. 121-8.

[30] Holt W. Fundamental aspects of sperm cryobiology: the importance of species and individual differences. Theriogenology 2000;50:47-50.

[31] Garde J, Aguado M, Garrido D, Montoro V, Pérez S, García-Artiga C. Determinación postmortem de la viabilidad y de la capacidad para penetrar ovocitos del semen de ciervo. In: VII Jornadas Internacionales de Reproducción Animal. Murcia, Spain; 1994. p. 117.

[32] Kaabi M, de Paz P, Alvarez M, Anel E, Boixo J, Rouissic H, et al. Effect of epididymis handling conditions on the quality of ram spermatozoa recovered post-mortem. Theriogenology 2003;56:1249-59.

[33] Gatti J, Chevrier C, Paquignon M, Dacheux J. External ionic conditions, internal pH and motility of ram and boar spermatozoa. J Reprod Fertil 1993;98:439-49.

[34] Holt W. Can we predict fertility rates? Making sense of sperm motility. Reprod Domest Anim 1996;31: $17-24$. 